\title{
Multi-walled carbon nanotubes as a solid-phase extraction adsorbent for the determination of chlorophenols in environmental water samples
}

\author{
Ya-qi Cai ${ }^{a}$, Yu-e Cai ${ }^{\text {a,b }}$, Shi-fen $\mathrm{Mou}^{\mathrm{a}, *}$, Yi-qiang $\mathrm{Lu}^{\mathrm{b}}$ \\ a State Key Laboratory of Environmental Chemistry and Ecotoxicology, Research Center for Eco-Environmental Sciences, \\ Chinese Academy of Sciences, Beijing 100085, China \\ ${ }^{\mathrm{b}}$ Department of Chemistry, University of Science and Technology Beijing, Beijing 100083, China \\ Received 26 January 2005; received in revised form 8 May 2005; accepted 11 May 2005 \\ Available online 13 June 2005
}

\begin{abstract}
Multi-walled carbon nanotubes (MWCNs) are used as adsorbent for solid-phase extraction (SPE) of several chlorophenols (CPs). CPs were adsorbed on MWCNs cartridge, then desorbed with $\mathrm{pH} 10.0$ methanol, finally determined by HPLC. Under the optimized conditions, detection limits of $0.08-0.8 \mathrm{ng} \mathrm{mL}^{-1}$ were obtained. The method had been applied to analyze the five CPs in tap water and river water.
\end{abstract}

(C) 2005 Elsevier B.V. All rights reserved.

Keywords: Multi-walled carbon nanotubes; Solid-phase extraction; HPLC; Chlorophenols; Water samples

\section{Introduction}

Carbon nanotubes, repeatedly discussed in the literature for the SPE of several organic contaminants [1-4] and trace metal ions [5], are now tested for the SPE of a limited number of CPs.

\section{Experimental}

\subsection{Reagents and water samples}

4-Chlorophenol (4CP) and 3-chlorophenol (3CP) $(1.00 \mathrm{mg} / \mathrm{mL})$ were purchased from the Institute for Reference Materials, Beijing, China. 2,4-Dichlorophenol (DCP), 2,4,6-trichlorophenol (TCP) and pentachlorophenol (PCP) were obtained from China State Research Center for Reference Materials, Beijing, China. LC-grade methanol and acetonitrile were purchased from Siyou Biomedical

\footnotetext{
* Corresponding author. Tel.: +86 1062849182 ; fax: +86 1062849239 .

E-mail address: shifenm@mail.rcees.ac.cn (S.-f. Mou).
}

Technology Co. Ltd. (Tianjing, China). The physical characterization of MWNTs used was described elsewhere [1].

Tap and river water were collected from the water tap in our laboratory and the Jingmi Canal, respectively, filtered through a $0.20 \mu \mathrm{m}$ cellulose membrane and then stored at a temperature of $4{ }^{\circ} \mathrm{C}$.

\subsection{Chromatographic system and conditions}

The HPLC instrument included a P680A gradient pump, an AS50 autosampler, a LC30 chromatography oven set at $30^{\circ} \mathrm{C}$ and an AD25 absorbance detector (Dionex, Sunnyvale, USA) set at $285 \mathrm{~nm}$. The separation was performed on a polar-enhanced $\mathrm{C}_{16}$ silica column $(150 \mathrm{~mm} \times 4.6 \mathrm{~mm}$ I.D., $5 \mu \mathrm{m}, 120 \AA$, Dionex, Sunnyvale, USA) at a flow rate of $1 \mathrm{~mL} / \mathrm{min}$. The gradient elution was performed with a mixture solution of acetonitrile and water $(20+80, v+v)$ containing $1 \%$ acetic acid (A) and acetonitrile containing $1 \%$ acetic acid (B). The gradient program was as follows: started at $10 \% \mathrm{~B}$, increased B to $55 \%$ in $15 \mathrm{~min}$, increased $\mathrm{B}$ to $100 \%$ in $5 \mathrm{~min}$ and kept for $5 \mathrm{~min}$, then decreased B to $10 \%$ in 1 min and kept for 2 min to equilibrate the column. 


\subsection{Extraction procedure}

The SPE cartridge packed $0.3 \mathrm{~g}$ MWCNs was prepared and pretreated by the method described elsewhere [1]. The solutions adjusted to $\mathrm{pH}$ neutral were loaded at a flow rate of $5 \mathrm{~mL} \mathrm{~min}^{-1}$. Then, CPs were eluted with $6 \mathrm{~mL}$ of $\mathrm{pH} 10.0$ methanol. Under a gentle stream of nitrogen gas, the eluate was evaporated to about $0.5 \mathrm{~mL}$, then its $\mathrm{pH}$ was adjusted to 3.0 and its volume was increased to $1.0 \mathrm{~mL}$ with methanol. Finally, $25 \mu \mathrm{L}$ of the solution was injected for the HPLC determination.

\section{Results and discussion}

\subsection{Evaluation of MWCNs as SPE sorbents}

\subsubsection{Choice of the kind and the volume of eluent}

Five types of eluents including methanol, acetonitrile, tetrahydrofuran, ethyl acetate and $\mathrm{pH} 10.0$ methanol were tested and the results are shown in Fig. 1. It is difficult to elute CPs quantitatively with methanol, acetonitrile, tetrahydrofuran and ethyl acetate alone. Of all five CPs, PCP was the most difficult one to be eluted. The experiments showed that $\mathrm{pH} 10.0$ methanol was the most effective eluent.

For extraction of $4 \mathrm{CP}, 3 \mathrm{CP}, \mathrm{DCP}$ and $\mathrm{TCP}$, when eluent volume was in the range of $1-2 \mathrm{~mL}$, the recoveries increased with increase of eluent volume; but when eluent volume was increased further, the recoveries leveled off. For extraction of PCP, only when eluent volume amounted to $5-6 \mathrm{~mL}$, did the recovery get to a higher level and level off. So, $6 \mathrm{~mL}$ of $\mathrm{pH}$ 10.0 methanol was adopted. In this case, recoveries of $92 \%$, $91 \%, 91 \%, 87 \%$ and $84 \%$ were achieved for $4 \mathrm{CP}, 3 \mathrm{CP}$, DCP, TCP and PCP, respectively.

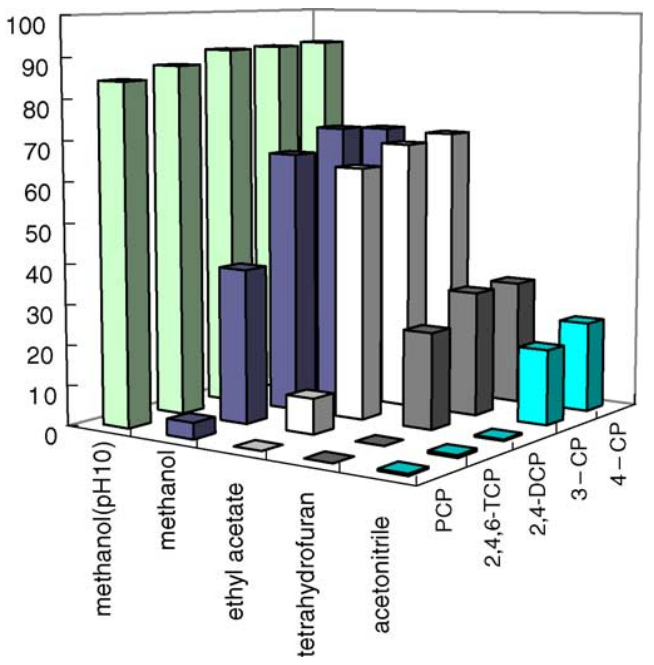

Fig. 1. Effect of types of eluents on the recoveries of five CPs. Volume of solutions: $50 \mathrm{~mL}$; concentration of five CPs: $400 \mathrm{ng} \mathrm{mL}^{-1}$.

\subsubsection{Effects of the $p H$ and volume of water samples on the extraction efficiency}

The effect of the $\mathrm{pH}$ was investigated over the range of $\mathrm{pH}$ 1-11 and it was found that very low and high $\mathrm{pH}$ of solutions had a negative effect on the extractions. But when the $\mathrm{pH}$ of solutions varies in the range of $\mathrm{pH} 5-9$, the $\mathrm{pH}$ nearly has no influence on the extractions. Therefore, $\mathrm{pH} 5-9$ was selected as the $\mathrm{pH}$ of solutions.

To investigate the influence of sample volume, different volumes of purified water were spiked with $20 \mu \mathrm{g}$ of five CPs. It was found that the recoveries decreased slightly with the increase of volume. When the volume was $200 \mathrm{~mL}$, the recoveries of $83-87 \%$ were obtained for the five CPs. For some special $\mathrm{CPs}$, such as $4 \mathrm{CP}$ and $3 \mathrm{CP}$, it appears that the recoveries obtained in the present work are better than those of other research work. In report [6], polyaniline was used for

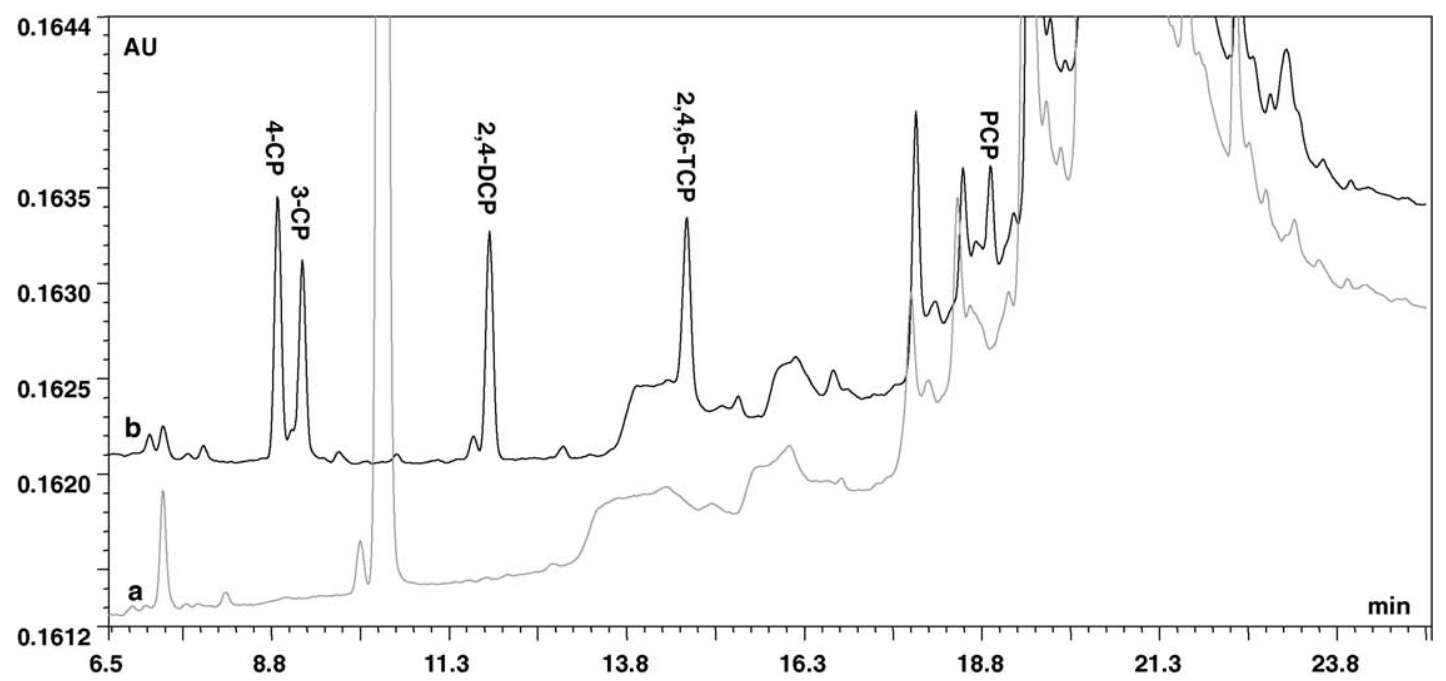

Fig. 2. SPE-LC chromatograms of tap water samples. (a) Tap water sample, and (b) tap water sample spiked with CP standards. See Table 2 for the spiked concentration level of CPs. 
Table 1

Recoveries at different volumes of sample solutions $(n=3)$

\begin{tabular}{llllll}
\hline Analyte & \multicolumn{5}{l}{ Volume $(\mathrm{mL})$} \\
\cline { 2 - 6 } & 50 & 100 & 200 & 500 & 1000 \\
\hline & \multicolumn{2}{l}{ Recoveries $(\%)$} & & & \\
$4 \mathrm{CP}$ & 92 & 90 & 86 & 76 & 73 \\
$3 \mathrm{CP}$ & 91 & 92 & 87 & 78 & 73 \\
DCP & 91 & 93 & 85 & 83 & 73 \\
TCP & 87 & 93 & 84 & 81 & 76 \\
PCP & 84 & 87 & 83 & 82 & 67 \\
\hline
\end{tabular}

SPE of several CPs, and recoveries were $45 \%$ and $55 \%$ for $2 \mathrm{CP}$ and $4 \mathrm{CP}$, respectively. In other cases, it appears that the recoveries are as good as those obtained with some polymer adsorbents [7-9]. In the analyses of water samples, a volume of $200 \mathrm{~mL}$ was selected.

\subsection{Analytical performance and application}

Under the optimized conditions, the analytical performance was examined. There is a linear correlation between peak area and concentration of $1-200 \mathrm{ng} / \mathrm{mL}$ for $4 \mathrm{CP}, 3 \mathrm{CP}$, DCP and TCP, $2-200 \mathrm{ng} / \mathrm{mL}$ for PCP, respectively. The detection limits $(\mathrm{s} / \mathrm{n}=3)$ of $0.08,0.1,0.1,0.2$ and $0.8 \mathrm{ng} / \mathrm{mL}$ were obtained for 4CP, 3CP, DCP, TCP and PCP, respectively.

The method was applied to analyses of tap and river water, and recoveries were in the range of $88-109 \%$. The chromatograms of a tap water and its spiked standard solution are shown in Fig. 2. It is noticed that baselines of these chromatograms is rather unusual: they are not smooth after $17.5 \mathrm{~min}$, but smooth before $17.5 \mathrm{~min}$. The reason for this is not yet clear. In view of this case, it is very difficult to get a low detection limit for PCP. As indicated above, the detection limit for the PCP is $0.8 \mu \mathrm{g} / \mathrm{mL}$, a much higher value than those of other four CPs.

\section{Conclusions}

MWCNs have been evaluated for SPE of trace CPs, and the recoveries were compared with those of other published
Table 2

Recoveries of five CPs spiked water samples $(n=3)$

\begin{tabular}{llr}
\hline Water sample & Added $\left(\mathrm{ng} \mathrm{mL}^{-1}\right)$ & Recovery $(\%)$ \\
\hline Tap water & & \\
4CP & 2.50 & $101 \pm 8$ \\
3CP & 2.50 & $103 \pm 6$ \\
DCP & 2.50 & $100 \pm 7$ \\
TCP & 2.50 & $100 \pm 6$ \\
PCP & 5.00 & $97 \pm 8$ \\
River water & & \\
4CP & 2.50 & $100 \pm 6$ \\
3CP & 2.50 & $99 \pm 5$ \\
DCP & 2.50 & $93 \pm 8$ \\
TCP & 2.50 & $88 \pm 6$ \\
PCP & 5.00 & $109 \pm 8$ \\
\hline
\end{tabular}

reports. The results showed that MWCNs could be used as an effective SPE sorbent for CPs (Tables 1 and 2).

\section{Acknowledgements}

This work was jointly supported by the National Basic Research Program of China (2003CB415001) and National Natural Science Foundation of China (20475060).

\section{References}

[1] Y. Cai, G. Jiang, J. Liu, Q. Zhou, Anal. Chem. 75 (2003) 2517.

[2] Y. Cai, G. Jiang, J. Liu, Q. Zhou, Anal. Chim. Acta 494 (2003) 149.

[3] Q. Li, D. Yuan, Q. Lin, J. Chromatogr. A 1026 (2004) 283.

[4] B. Fugetsu, S. Satoh, A. Iles, K. Tanaka, N. Nishi, F. Watari, Analyst 129 (2004) 565.

[5] P. Liang, Y. Liu, L. Guo, J. Zeng, H. Lu, J. Anal. At. Spectrom. 19 (2004) 1489.

[6] H. Bagheri, M. Sarahi, J. Chromatogr. A 910 (2001) 87.

[7] I. Rodriguez, M.C. Mejuto, M.H. Bollain, R. Cela, J. Chromatogr. A 786 (1997) 285.

[8] H. Bagheri, A. Mohammadi, J. Chromatogr. A 1015 (2003) 23.

[9] H. Bagheri, M. Sarahi, J. Chromatogr. A 986 (2003) 111. 